NOTA CIENTÍFICA

\title{
Efecto de Brugmansia arborea (L.) Lagerheim (Solanacea) en el sistema reproductor masculino de ratón
}

\section{Effects of Brugmansia arborea (L.) Lagerheim (Solanacea) in the male reproductive system of mouse}

\author{
José Pino y Rafael Alvis
}

Laboratorio de Reproducción y Biología del Desarrollo, Facultad de Ciencias Biológicas, Universidad Nacional Mayor de San Marcos Lima, Perú. Casilla 11-058, Lima 11, Perú. E-mail José Pino: jpinog@ unmsm.edu.pe

Presentado: $18 / 08 / 2008$ Aceptado: $26 / 11 / 2008$ Publicado online: 26/02/2009

\section{Resumen}

El objetivo del presente estudio fué investigar el efecto de la administracion del extracto acuoso de Brugmansia arborea (L.) Lagerheim -floripondio-sobre algunos parámetros reproductivos en mamíferos. Ratones machos fueron tratados con $70 \mathrm{mg} / \mathrm{kl} / \mathrm{pc}$ por 7 días, después de lo cual fueron eutanizados determinando los pesos de testículo, epidídimo e individualmente su región caudal; además, se contabilizó la concentración y malformaciones espermáticas. El peso del testículo y la cola del epidídimo disminuyeron; la concentración espermática fue menor que el control, se incrementaron las malformaciones espermáticas. Estos resultados sugieren que existe un efecto negativo de la dosis de $B$. arborea que alteraría la fertilidad del ratón.

Palabras Clave: Brugmansia arborea, floripondio, Datura, fertilidad.

\section{Abstract}

The aim of this study was to investigate the effect of administration of aqueous extract of Brugmansia arborea (L.) Lagerheim-Angel's Trumpet-on some reproductive parameters in mammals.Male mices were treated with $70 \mathrm{mg} / \mathrm{kl} / \mathrm{cw}$ for 7 days, where they were euthanized and its testis, epididymis and its cauda region weights where determinate; so, the sperms number and its abnormalities were accounted. The testis and epididymis tail weight fell; sperm concentration was lower than control and the abnormalities rises. These results suggest that there is a negative effect of the dose of $B$. arborea than would alter the fertility of the mouse.

Keywords: Brugmansia arborea, Angel's Trumpet, Datura, fertility.

\section{Introducción}

Las plantas medicinales continúan siendo una fuente importante de nuevas sustancias que poseen efectos terapéuticos; actualmente, cerca de la mitad de los fármacos en uso derivan de productos naturales (Oluyemi et al., 2007; Parker et al., 2007).

En las últimas décadas, la toxicología del aparato reproductor masculino se ha convertido recientemente en un área de estudio y de pruebas para nuevos productos terapéuticos provenientes de plantas medicinales. (Gimmler-Luz \& Erdtmann, 1998; Ghosh et al., 2002; Salman \& Adesokan, 2008); especialmente, los principios activos que actúan como disruptores endocrinos; entre ellos, los alcaloides antimuscarínicos (antagonistas de receptores muscarínicos).

Todas las especies del género Brugmansia han sido utilizadas como alucinógenos desde tiempos precolombinos, principalmente en los Andes y en la Amazonía: como diagnóstico (rituales mágicos) (De Feo, 2003; Bussmann \& Sharon, 2006) y para tratar enfermedades (Capasso \& De Feo, 2003; Lenaerts, 2006). Recientemente, Ianaconne et al., (2004) y Iannacone \& Quispe (2004) evaluaron la aplicación de $B$. candida como biocida.

Las Brugmansias contienen diversos alcaloides como escopolamina, nioscamina, atropina, hyocine, hyosciamina, norhyocine, apohyocine, (-)-3a-Tigloyloxy-6 -acetoxytropane, d3a-Acetoxytropane (Evans \& Mayor, 1966; Richter et al., 2005) y los variados alcaloides del grupo tropano, tales como norescopolamina, aposcopolomina, metelodina (Zayed \& Wink, 2004). Siendo la escopolomina la que aparece en mayor proporción (Dickel, 2006).

Brugmansia arborea (Linn.) (= Datura arborea) pertenece a la familia de las solanaceae; se le conoce localmente como "floripondio" y es nativa de Mesoamérica (Symon \& Haegi, 1991), actualmente esta distribuida en los continentes americano y europeo. De acuerdo a De Feo (2003), sus hojas frescas son usadas para tratar granos y otras erupciones de la piel, además se utiliza como apósito para tratar áreas dolorosas en el caso de inflamaciones reumáticas u otros traumas, los vapores de la decocción de las hojas se utilizan como antiséptico vaginal.

Brugmansia arborea contiene, como otras especies, los alcaloides tropano como la atropina y escopolamina, ambos conocidos ampliamente como antimuscarinicos (bloquean los receptores de acetilcolina). Ban et al., (2002) y Sato et al., (2005) aplicaron 62,5 y $125 \mathrm{mg} / \mathrm{kg} /$ día de atropina en ratas machos por una semana, encontrando un deterioro en la fertilidad de los mismos, concluyendo que los antagonistas de los receptores muscarinicos como la atropina inhiben la contracción de los vasos deferentes, epidídimo y de la vesícula seminal en ratas, causando infertilidad.

La neurotransmisión colinérgica es requerida dentro de los eventos reproductivos para varios procesos (proliferación celular, diferenciación, desarrollo y función de los órganos reproductores) (Siu et al., 2006). La mayoría de investigadores en esta área se concentran en la acción de los agonistas colinérgicos en el transporte seminal (Borges et al., 2001; Sato et al., 2005; Siu et al., 2006).

Sin embargo, algunos aspectos de la toxicidad del floripondio, tales como sus efectos sobre la espermatogénesis no esta bien estudiado. Se han ubicado receptores colinérgicos en espermatozoides de humanos (Peterson \& Freund, 1975), carnero (Stewart $\&$ Forrester, 1978) y ratones (Florman \& Storey, 1982), entre otros con una función aun no clara.

El incremento en el uso de las plantas medicinales en los últimos tiempos, hace necesario el estudio de su toxicidad como 
Tabla 1. Efecto del extracto acuoso de Brugmansia arborea en los pesos de testículo, epidídimo y cola del epidídimo tras 7 días de tratamiento. Media \pm DS

\begin{tabular}{l|c|c|c}
\hline Individuos & peso testicular & peso del epididimo & peso de la cola \\
\hline Control & $0,1277 \pm 0,0025$ & $0,0377 \pm 0,0021$ & $0,0126 \pm 0,0009$ \\
\hline Tratamiento & $0,0989 \pm 0,0691^{*}$ & $0,0338 \pm 0,0028$ & $0,0101 \pm 0,0007^{*}$ \\
\hline ControlPositivo & $0,1063 \pm 0,0033$ & $0,0219 \pm 0,0239$ & $0,0099 \pm 0,0002$ \\
\hline
\end{tabular}

* $\mathrm{p}<0,05$, Tratamiento vs controles; Prueba paramétrica de Tukey.

parte del proceso de bioseguridad para el uso y tratamiento con plantas medicinales.

El objetivo del presente estudio es determinar el efecto sobre algunos parámetros reproductivos en ratones sometidos a la ingestión por 7 días del extracto crudo de las hojas del floripondio (B. arborea).

\section{Material y métodos}

Brugmansia arborea fue obtenido en comercios locales (Lima, Perú), e identificado en el Departamento de Botánica de la Facultad de Ciencias Biológicas de la Universidad Nacional Mayor de San Marcos. Las hojas fueron secadas en una estufa a $70{ }^{\circ} \mathrm{C}$ por $72 \mathrm{~h}$, luego pesadas y pulverizadas; el polvo fue dejado reposar en agua destilada por $24 \mathrm{~h}$ a $55^{\circ} \mathrm{C}$ para obtener el extracto acuoso, el cual fue decantado, filtrado y guardado a $-20{ }^{\circ} \mathrm{C}$.

Se utilizaron ratones de 6 a 10 semanas de edad de la cepa Albina Swiss Rockefeller. Los animales fueron mantenidos bajo condiciones estándar de bioterio; con $22-24^{\circ} \mathrm{C}$ de temperatura, fotoperíodo de $14 \mathrm{~h}$ luz: $10 \mathrm{~h}$ oscuridad, con libre acceso al alimento (Purina-Perú) y agua ad libitum.

Los ratones fueron divididos en tres grupos: el grupo tratado (T) $(\mathrm{n}=10)$ que recibió intraperitonalmente (ip) $70 \mathrm{mg}$ del extracto acuoso $/ \mathrm{kg}$ de peso corporal durante 7 días, un grupo control $(\mathrm{C})(\mathrm{n}=10)$ que recibió sólo agua destilada ip durante el mismo período de tiempo y un grupo Control Positivo (CP) $(\mathrm{n}=10)$, el cual recibió ip $150 \mathrm{mg} / \mathrm{kg}$ de ciclofosfamida.

Al séptimo día, los ratones de los tres grupos fueron eutanizados por dislocación cervical. Los testículos, el epidídimo y la cola del epidídimo fueron pesadas; luego de homogenizar la cola del epidídimo en solución PBS ( $\mathrm{pH} 7,2)$, se hizo el conteo espermático en la cámara de Neubauer.

Se realizaron dos frotices por ratón para determinar el porcentaje de malformaciones en los espermatozoides (CP, T y CN), coloreándolos en una solución acuosa de Eosina Y al 0,5\%. Los preparados fueron revisados en un microscopio óptico de campo claro y se tomaron fotos digitales.

Los datos de los pesos y concentración espermática fueron contrastados con ANOVA, mientras para los datos de morfología espermática se utilizó el test de Kolmogorov-Smirnov. Análisis

Tabla 2. Efecto del tratamiento de extracto acuoso de hojas de Brugmansia arborea en la concentracion espermatica en ratón.

\begin{tabular}{lc}
\hline & Media \pm DS \\
\hline Control & $14,045 \times 10^{6} \pm 2,594 \times 10^{6}$ \\
tratamiento & $5,440 \times 10^{6} \pm 3,164 \times 10^{6 *}$ \\
control positivo & $5,125 \times 10^{6} \pm 2,676 \times 10^{6}$ \\
\hline
\end{tabular}

* $p<0,05$, Tratamiento vs controles; Prueba paramétrica de Tukey y Bonferroni. post hoc con los Test de Bonferroni y Tukey, fueron utilizados para comprobar las fuentes de variación. Un nivel de $\mathrm{p}<0,05$ fue considerado significativo.

\section{Resultados}

Se encontró que existen diferencias entre los pesos del testículo y la cola del epidídimo con respecto al control negativo. No se encontró diferencia significativa entre el peso del epidídimo y el control negativo. (Tabla 1).

Con respecto al efecto del extracto acuoso de $B$. arborea sobre la concentración espermática, se observa que hay un efecto negativo en aquellos individuos que han sido tratados (Tabla 2).

Se observo una relación dosis-efecto en el incremento de espermatozoides anormales (amorfos, dos colas, cabeza inflada, redonda, ovaladas, bicefalia) con respecto al grupo control (Tabla 3).

\section{Discusión}

La medicina herbal ha llegado a ser una forma popular de terapia en muchos países. Si bien se promueve su venta en diferentes presentaciones como productos naturales u orgánicos; libres de efectos secundarios, no significa que estén exentos de causar toxicidad (Dalsenter et al., 2004). El presente estudio se realizó para evaluar la posible toxicidad reproductiva del extracto acuoso de hojas de B. arborea.

No se encontró efecto sobre la ganancia de peso corporal (dato no publicado); ni alteración clínica o en el comportamiento del animal, sugiriendo que el extracto acuoso no induce a una toxicidad sistémica en la dosis propuesta.

Es sabido que para que exista una variación significativa del peso de los órganos blanco, tiene que haber sucedido un daño sustancial en los mismos; los alcaloides de $B$. arborea no están catalogados como hormonalmente activos (isoflavonas o fitoestrógenos), sino como neuro-fisiológicamente activos (anticolinérgicos). La disminución del peso de las gónadas; epidídimo y cola del epidídimo en el grupo tratado puede ser debido a una disminución plasmática de gonadotropinas hipofisiarias y la testosterona, éstos índices de crecimiento son controlados por el nivel plasmático de las gonadotropinas hipofisiarias y a la testosterona (Ghosh et al., 2002; Sharma \& Bhinda, 2005).

El número de espermatozoides de la cola del epidídimo fue afectado, indicando un efecto negativo en el proceso espermatogénico. Los resultados sugieren que a los 7 días post tratamiento intraperitoneal con una dosis de $70 \mathrm{mg} / \mathrm{kg}$ del extracto acuoso de hojas de B. arborea, se afectarían los estadios espermatogénicos de espermatozoide y de espermátide tardía, posiblemente alterándose la condensación de la cromatina espermática, ocasionando un conteo bajo de espermatozoides, un aumento de malformaciones y de gota citoplasmática. 
Tabla 3. Efecto del tratamiento del extracto acuoso de hojas de Brugmansia arborea en las malformaciones espermaticas. A=dos cabezas; $\mathrm{B}=$ cabeza de balón; $\mathrm{C}=$ amorfos; $\mathrm{D}=$ dos colas; $\mathrm{E}=$ gota citoplasmatica. Media $\pm \mathrm{DS}$.

\begin{tabular}{lccccc}
\hline Individuos & Normales & A & B & C & E \\
\hline Control & $96,80 \pm 0,327$ & $1,50 \pm 0,5$ & $1,00 \pm 0,00$ & $1,86 \pm 0,261$ & $0,00 \pm 0,00$ \\
Tratamiento & $80,30 \pm 1,438^{*}$ & $2,11 \pm 0,351$ & $3,11 \pm 0,564$ & $5,60 \pm 0,748^{*}$ & $1,89 \pm 0,389$ \\
Control Positivo & $72,70 \pm 1,023$ & $3,10 \pm 0,233$ & $2,70 \pm 0,423$ & $6,30 \pm 0,932$ & $2,20 \pm 0,327$ \\
\hline
\end{tabular}

${ }^{*} \mathrm{p}<0,05$, Tratamiento vs controles; Prueba paramétrica de Tukey y Bonferroni.

La aparente baja de hormonas gonadotropas, disminución de la concentración de espermatozoides a nivel de la cola del epidídimo y aumento de malformaciones y gota citoplasmática, se explicaría por el bloqueo de los receptores muscarinicos a nivel del tracto reproductor, especialmente el testículo (Borges et al., 2001), principal órgano secretor de testosterona, sustancia determinante en la espermatogénesis y funcionamiento de los órganos reproductores.

A la luz de los resultados, se sugiere mayores estudios a nivel bioquímico y molecular a fin de establecer el nivel y relevancia del efecto de los efectos secundarios de los principios activos de plantas de uso medicinal.

\section{Literatura citada}

Ban Y., T. Sato, T. Nakatsuka, M. Kemi, K. Samura, et al. 2002. Impairment of male fertility induced by muscarinic receptor antagonists in rats. Reproductive Toxicology 16 (6): 757-765.

Borges M., M. Abreu, C. Porto \& M. Avellar. 2001. Characterization of Muscarinic Acetylcholine Receptor in Rat Sertoli Cells. Endocrinology 142(11): 4701-4710

Bussmann R. \& D. Sharon. 2006. Traditional medicinal plant use in Northern Peru: tracking two thousand years of healing cultura. Journal of Ethnobiology and Ethnomedicine 2:47 [http://www.ethnobiomed.com/content/2/1/47].

Capasso A. \& V. De Feo. 2003. Alkaloids from Brugmansia arborea (L.) Lagerheim reduce morphine withdrawal in vitro. Phytotherapy Research 17 (7): 826-829.

Dalsenter P., Cavalcanti, A., Andrade, A., Araújo, S. and M. Marques. 2004. Reproductive evaluation of aqueous crude extract of Achillea millefolium L. (Asteraceae) in Wistar rats. Reproductive Toxicology 18: 819-823

De Feo V. 2003. Ethnomedical field study in northern Peruvian Andes with particular reference to divination practices. Journal of Ethnopharmacology 85: 243-256

Dickel O. 2006. Efeitos comportamentais e genotóxicos em ratos Wistar sob efeito do extrato aquoso bruto de flores da B. suaveolens (Solanaceae). título de MESTRE em Fisiologia Animal Comparada. Programa de Pós-Graduação em Ciências Fisiológicas - Fisiologia Animal Comparada. 40 pp.

Evans W. \& V. Major. 1966. The Alkaloids of the Genus Datura, Section Brugmansia. Part IV. Alkaloids of D. sanguinea R. and P. Journal of Chemical Society: $1621-1623$.

Florman H. \& B. Storey. 1982. Characterization of Cholinomimetic Agents that Inhibit In Vitro Fertilization in the Mouse. Journal of Andrology 3: 157-164.

Gimmler-Luz M. \& B. Erdtmann. 1998. Effects of Pirrolizidine Alkaloid, Integerrimine, on mouse sperm morphology. Revista Internacional de Contaminacion Ambiental 14(2): 79-83.

Gosh D., D. Jana, \& J. Debnath. 2002. Effects of leaf extract of Stephania hernandifolia on testicular gametogenesis and androgenesis in albino rats: a dose-dependent response study. Contraception 65: 379-384.
Iannacone J., H. Ayala, J. Alvarez, O. Leyva \& E. Bajalque. 2004. Cuatro plantas biocidas sobre Sitophilus zeamais y Stegobium paniceum en el Perú. Wiñay Yachay (Perú) 8: $16-27$.

Iannacone J. \& C. Quispe. 2004. Efecto insecticida de dos extractos vegetales sobre el gorgojo del maíz, Sitophilus zeamais Motschulsky, 1855 (Coleoptera: Curculionidae) en Perú. Revista Peruana de Entomología 44: 81-87.

Lenaerts M. 2006. Substances, relationships and the omnipresence of the body: an overview of Ashéninka ethnomedicine (Western Amazonia). Journal of Ethnobiology and Ethnomedicine 2:49.

Oluyemi K., U. Okwuonu, G. Baxter \& T. Oyesola. 2007. Toxic effects of methanolic extract of Aspilia africana leaf on the estrous cycle and uterine tissues of Wistar rats. International Journal of Morphology 25(3): 609-614.

Parker A., G. Peraza, J. Sena, E. Silva, M. Flores, et al. 2007. Antinociceptive Effects of the Aqueous Extract of Brugmansia suaveolens Flowers in Mice. Biological Research for Nursing. 8 (3): 234-239.

Peterson R. \& M. Freund.1975. The Inhibition of the Motility of Human Spermatozoa by Various Pharmacologic Agents. Biology of Reproduction 13: 552-556

Richter U., G. Rothe, A. Fabian, B. Rahfeld \& B. Dräger. 2005. Overexpression of tropinone reductases alters alkaloid composition in Atropa belladonna root cultures. Journal of Experimental Botany 56 (412): 645-652.

Salman T. \& A. Adesokan. 2008. Sperm quality of male rats treated with aqueous extract of Enantia chlorantha stem bark. African Journal of Biotechnology 7(7): 865-867.

Sato T., Y. Ban, M. Uchida, E. Gondo, M. Yamamoto, et al. 2005. Atropine-induced inhibition of sperm and semen transport impairs fertility in male rats. The Journal of Toxicological Science 30(3): 207-212.

Sharma J. \& A. Bhinda. 2005. Antifertility Activity of Steroidal Extract of Trigonella foenum-graecum (seeds) in Female Rats. Asian Journal of Experimental Science 19(1): 115120.

Siu E., F. Yasuhara, E. Maróstica, M. Avellar \& C. Porto. 2006. Expression and localization of muscarinic acetylcholine receptor subtypes in rat efferent ductules and epididymis. Cell Tissue Research 323: 157-166.

Stewart T. \& I. Forrester. 1978. Identification of a Cholinergic Receptor in Ram Spermatozoa. Biology of Reproduction 19: 965-970.

Symon D. \& L. Haegi. 1991. Datura (Solanaceae) is a New World Genus. p. 197-210. In: Solanaceae III, Taxonomy, Chemistry, Evolution. Hawkes, J.G., Lester, R.N., Nee, M. and Estrada-R., N. (eds). Publication of the Royal Botanic Gardens, Kew, UK for the Linnaean Soc. of London.

Zayed R. \& M. Wink. 2004. Induction of Tropane Alkaloid Formation in Transformed Root Cultures of Brugmansia suaveolens (Solanaceae). Z. Naturforsch. 59c: 863-867. 


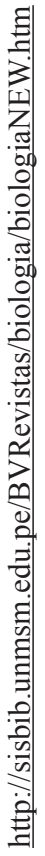

